\title{
CONTRIBUIÇÃO DO PIBID PARA A PRÁTICA PROFISSIONAL: aprendizagens da docência por homologia na formação inicial
}

\author{
Fabrício Oliveira da Silva? \\ Ingrid da Silva Alves ${ }^{2}$
}

\section{RESUMO}

Este artigo trata das aprendizagens tecidas pelas relações que o sujeito vivencia durante o processo de formação inicial para a docência, com especial foco nas contribuições do Programa Institucional de Bolsas de Iniciação à Docência - PIBID. Tem como objetivo compreender o processo de aprendizagem docente dos licenciandos a partir das relações obtidas pela ação homológica que se estabelece entre professores em formação inicial e professores em exercício na Educação Básica. O artigo fundamenta-se nos princípios da pesquisa qualitativa, tendo as entrevistas narrativas enquanto dispositivo de pesquisa. As discussões foram feitas com base nas reflexões de Silva (2017), Freire (1996), Minayo (2008), Dutra (2010) dentre outros, que abordam características sobre as aprendizagens relacionais na formação inicial. Como resultado, o estudo evidencia que essas relações presentes no ambiente escolar influenciam diretamente na aprendizagem do ser docente e também no processo de construção identitária do licenciando em formação.

Palavras-chave: Aprendizagens experienciais. Homologia. Formação inicial. Docência na educação básica.

\section{PIBID CONTRIBUTION TO PROFESSIONAL PRACTICE: learning of teaching by}

\section{homology in initial teacher education}

\begin{abstract}
This article deals with learnings built by the relationships the subject experiences during the initial teacher education process, with a special focus on the contributions of the Institutional Program of Teaching Initiation - PIBID. It aims to understand the undergraduate students' learning process from the relationships obtained by the homological action that is established between teachers in initial education and

\footnotetext{
1 Doutorado em Educação e Contemporaneidade. Professor Adjunto da Universidade em Educação - PPGE/UEFS. Feira de Santana, Bahia, Brasil. Orcid iD: https://orcid.org/00000002-7962-7222. E-mail: fosilva@uefs.br

2 Licencianda em Pedagogia pela Universidade Estadual de Feira de Santana - UEFS. Feira de Santana, Bahia, Brasil. Orcid iD https://orcid.org/0000-0001-5282-179X. E-mail:

ingrids.alves@hotmail.com
} Estadual de Feira de Santana - UEFS. Professor Permanente do Programa de Pós-Graduação
\end{abstract}


teachers in service in Basic Education. The article is based on the principles of qualitative research, with narrative interviews as a research device. The discussions were made based on Silva (2017), Freire (1996), Minayo (2008), Dutra (2010), among others, who address characteristics about relational learning in initial teacher education. As a result, the study shows that these relationships present in the school environment influence directly the teacher in initial education's learning and process of identity construction.

Keywords: Experiential learning. Homology. Initial teacher education. Teaching in basic education.

\section{CONTRIBUCIÓN DEL PIBID A LA PRÁCTICA PROFESIONAL: aprendizaje de la enseñanza por homología en la formación inicial}

\section{RESUMEN}

Este artículo tiene como objetivo analizarlos aprendizajes entretejidos por las relaciones que se observan en la asignatura durante el proceso de formación inicial para la docencia, con especial énfasis en los aportes del Programa Institucional de Becas de Iniciación Docente PIBID. TSe trata de comprender el proceso de enseñanza aprendizaje de los estudiantes de pregrado a partir de las relaciones obtenidas por la acción homológica que se establece entre los docentes en formación inicial y los docentes en práctica en Educación Básica. Este trabajo se sustenta en los principios de la investigación cualitativa, en el cual se utilizan entrevistas narrativas como dispositivo de investigación. Las discusiones se realizaron a partir de las reflexiones de autores como Silva (2017), Freire (1996), Minayo (2008), Dutra (2010) entre otros, que abordan características sobre el aprendizaje relacional en la formación inicial. Los resultados de este estudio advierten que que estas relaciones presentes en el ámbito escolar, influyen directamente en el aprendizaje del docente, as $\div$ i como en el proceso de construcción identitaria del pregrado en formación.

Palabras clave: Aprendizaje experiencial. Homología. Formación inicial. Docencia en educación básica.

\section{INTRODUÇÃO}

A formação inicial de professores, compreendida no cenário das trajetórias de vida e formação de licenciandos no Programa Institucional de Bolsas de Iniciação à Docência - PIBID, segundo Silva (2017), constrói-se a partir de um movimento que insere o sujeito no cotidiano da escola e o faz conviver em meio às produções das atividades escolares, em que conhecimentos da docência vão sendo tecidos e gerando espaço para a produção de experiências, consideradas uma espécie de alicerce para as 
reflexões que o licenciando produz sobre si, no percurso de sua própria formação.

Nesse cenário, a aprendizagem da docência é constituída, também, pelas relações que se estabelecem entre os indivíduos no processo de formação inicial. São relações que se evidenciam em diferentes focos, mas que convergem para singularidades do campo da docência. Assim, são relações entre professores em exercício e licenciando; relações de saberes no campo da teoria e prática, bem como relações que se evidenciam nas práticas cotidianas do fazer docente.

Desse modo, através dessas relações os sujeitos vão conquistando experiências educativas, as quais são aprendidas e apreendidas, consequentemente, pelo processo de homologia, que aqui, figurativamente, significa aprendizagem da docência na/pela relação entre professores em formação inicial e professores que já atuam na profissão em contextos cotidianos de atuação da docência. Assim sendo, a homologia é entendida como um modo de aprender com o outro, na convivência diária do tecer a profissão docente. Por homologia, no sentido figurado, a aprendizagem ocorre no ambiente de trabalho, motivada pela relação que o licenciando estabelece com o professor da educação básica, entendido como coformador.

De tal modo, percebe-se que as relações adentram a diversos contextos educativos, evidenciando singularidades que são vivenciadas por quem está aprendendo a ser professor, em franca formação inicial. Nesse cenário, evidenciam-se multiplicidades de meios que o licenciando se insere para aprender sobre a docência e o fazer docente. Tal dinâmica sugere que há significâncias peculiares para cada aprendente, pois cada um pode se relacionar com um determinado fator de formar e graus diferentes de compreensão dos fenômenos educativos, logo de aprendizagens, a que chamamos de experienciais.

Segundo Silva (2017) as aprendizagens experienciais são aquelas que se logram nas acontecências da escola, pois, como assevera o referido autor, 
A escola apresenta várias situações de relacionamento interpessoal que fazem com que o sujeito aprenda a conviver em um espaço coletivo, acatando e emitindo opiniões, produzindo reflexões e desenvolvendo senso crítico. Nessa seara, o professor vê a escola como um espaço de socialização, de troca de experiências, saberes e desenvolvimento de aprendizagem (SILVA, 2017, p. 164).

Isto posto, compreende-se que a escola é um espaço inteiramente relacional e contribui para que o sujeito construa suas relações de acordo as experiências vivenciadas. Nesse movimento, além de aprender com o outro como menciona Silva (2017), ao estabelecer uma rotina diária nesse ambiente, o licenciando também estabelece relações com o cotidiano, visualizando todas as dinâmicas, organizações, observando como decorrem as posturas dos sujeitos presentes (SILVA; RIOS, 2018).

Outro fator relacional que se evidencia no âmbito das aprendizagens experienciais da docência, diz respeito à relação teoria e prática que surge quando esse sujeito passa a vivenciar o cotidiano escolar e se relacionar com indivíduos pertencentes aquele espaço. A partir disso, o estudante através das práticas produzidas no âmbito do dia a dia escolar começa a visualizar conceitos e ideias que se ancoram em situações já discutidas e compreendidas no campo universitário. Esse processo estabelece uma aprendizagem mais significativa, coerente e reflexiva para $\circ$ professor em formação. A relação teoria e prática se fundamenta num princípio de indissociação, conforme compreende Dutra (2010, p.42), ao afirmar que:

Teoria e prática são componentes indissociáveis, pois apesar de diferentes, a teoria como pensamento da prática, é fundamental para a compreensão, a elucidação e a própria transformação da sociedade e para a prática continuamente se voltam como seu ponto de partida e finalidade.

Logo, devido às implicações apresentadas, este artigo tem como objetivo compreender $\mathrm{O}$ processo de aprendizagem docente dos licenciandos a partir das relações obtidas pela ação homológica das práticas presentes na formação inicial. No decorrer das discussões, entendese que as aprendizagens sobre o ser professor emergem de relações que o 
licenciando vai estabelecendo durante todo o período formativo e pela possibilidade do PIBID inserir o estudante no cotidiano escolar, no qual é o lócus das aprendizagens da docência. Assim ao compreender as inferências, buscamos analisar a seguinte questão: De que maneira os licenciandos constroem o conhecimento sobre a docência a partir das relações homológicas vivenciadas no cotidiano escolar?

O presente artigo é um recorte da pesquisa intitulada: "Aprendizagem da docência por homologia: Relação professor e licenciando", que está em fase de conclusão e sendo realizada no âmbito do Núcleo de Estudos e Pesquisas sobre Pedagogia Universitária - NEPPU da Universidade Estadual de Feira de Santana - UEFS/BA.

O texto, além da introdução, parte em que enunciamos a problemática e os objetivos da pesquisa, estrutura-se em outras quatro grandes seções. Na primeira discorremos sobre os percursos metodológicos, apresentando o cenário da pesquisa com foco aos dispositivos e base epistemológica do estudo. Na segunda, discorremos sobre o histórico e objetivo do PIBID, elucidando o modo como o referido Programa foi pensado na ótica de otimizar a relação escola básica e universidade, bem como a relação teoria e prática. Na terceira seção, reunimos os resultados e as discussões, ancorando a análise, compreensiva e interpretativa, com foco no que concebem professores e licenciandos sobre as aprendizagens experienciais da docência. Por fim, mas não menos importante, apresentamos as considerações finais, evidenciando os achados da pesquisa.

\section{PERCURSO METODOLÓGICO}

O artigo fundamenta-se nos princípios da pesquisa qualitativa, defendida por Minayo (2008), na qual se destaca a importância da subjetivação, pois durante a investigação científica é preciso reconhecer a complexidade do objeto de estudo, rever criticamente as teorias sobre o tema, estabelecer conceitos e teorias relevantes, usar técnicas de coleta de 
informações adequadas e, por fim, analisar todo o material de forma específica e contextualizada.

Assim, na pesquisa qualitativa, o estudo dos sentidos sobre a experiência humana deve ser feito entendendo que as pessoas interagem, interpretam e constroem compreensões sobre o que são e o que fazem. No caso deste trabalho, a abordagem qualitativa nos ajudou a compreender mediante as narrativas de uma professora em exercício e de licenciandos como as relações são definidas na aprendizagem docente por homologia.

Como dispositivo de pesquisa, foram utilizados relatos narrativos de três estudantes e uma professora, os quais foram produzidos em momentos individualizados. Em virtude da necessidade de se manter os anonimatos desses participantes, foram usados nomes fictícios. Os relatos refletem diálogos a respeito das questões de aprendizagem da docência por homologia da prática. Assim sendo, os relatos evidenciam informações decorridas das relações que os aprendentes, consequentemente, estabeleceram com a professora em exercício, ao que tange à aprendizagem por homologia.

Os relatos narrativos se derivam da entrevista narrativa, um instrumento utilizado para colher informações, no qual o sujeito relata sobre algum fato que a princípio foi, brevemente, no início da entrevista, apenas contextualizado pelo pesquisador. A partir disso, o sujeito narra, por meio das suas experiências, situações, práticas e vivências que ele mesmo elege para narrar e atribuir sentidos, no próprio movimento narrativo pelo qual enreda os fenômenos vivenciados.

O gênero entrevista narrativa caracteriza-se, em sua estrutura inicial, por uma contextualização da situação a ser narrada e não, necessariamente, por perguntas feitas ao entrevistado. A contextualização do conteúdo da narrativa possibilita, àquele que narra, fluir de forma livre sobre as experiências que decide trazer à baila. Cria-se uma condição para que o colaborador discorra sobre o assunto eleito de forma autônoma, podendo explorar e aprofundar mais suas ideias. Desse modo Jovchelovitch e Baver $(2002$, p.91) afirmam: 
Através da narrativa, as pessoas lembram o que aconteceu, colocam a experiência em uma sequência, encontram possíveis explicações para isso, e jogam com a cadeia de acontecimentos que constroem a vida individual e social. Contar histórias implica estados intencionais que aliviam, ou ao menos tornam familiares, acontecimentos e sentimentos que confrontam a vida cotidiana normal.

Diante disso, a entrevista narrativa é caracterizada como o método de pesquisa qualitativa, sendo estabelecido um processo de uma entrevista não estruturada com informações aprofundadas. Suas particularidades variam de acordo com o discurso mencionado pelo sujeito entrevistado no qual conceitualmente, a ideia da entrevista narrativa tem como foco a narratividade livre, tencionada e demarcada pelos próprios movimentos reflexivos que quem narra produz.

Nessa perspectiva, Jovchelovitch e Baver (2002) discutem que a entrevista narrativa se constrói através de quatro fases: a iniciação, narração, tensionamentos do próprio narrador e conclusão. Logo, esse dispositivo permitiu analisar todas as informações narradas pelos colaboradores. O perfil desses participantes centralizou em três estudantes do curso de licenciatura em Pedagogia, bolsistas do programa PIBID e uma professora supervisora, responsável por acompanhar a formação dessas estudantes durante o período de vigências da bolsa. A coleta de informações foi realizada no período dos meses de março e abril de 2020, no qual duas delas ocorreram presencialmente no campus da universidade. Ressalte-se que devido as condições de isolamento físico, provocado pelos decretos governamentais em combate a proliferação do vírus covid-19, as entrevistas da terceira estudante e da professora ocorreram por meio de plataformas virtuais (Team link).

Para a efetivação das análises das informações, nos inspiramos no paradigma compreensivo e interpretativo. Assim, $O$ processo de categorização foi constituído a partir dos núcleos temáticos que emergiam da própria narrativa, observando-se o foco que cada colaborador produziu no momento de narrar as experiências e vivências com o PIBID. Assim sendo, as análises tiveram como aporte as contribuições do método compreensivo- 
interpretativo. Trata-se de uma análise, que para Ricoeur (1996), constitui-se a partir dos efeitos da compreensão, que é resultado de uma explicação que se dá para as coisas humanas e, também, não humanas. Isso sugere que a explicação, antes da própria compreensão, é a tradução da realidade num significado que tenha sentido e se processe por uma determinada linguagem, ou signos linguísticos que nos permitam e possibilitem uma comunicação compreensiva do real.

\section{HISTÓRICO E OBJETIVO DO PIBID}

O PIBID foi lançado, em sua primeira versão, em dezembro de 2007, por meio de um edital que tinha como principal objetivo atender as demandas de formação de licenciandos, nas áreas de Ciências Exatas e Naturais. A justificativa para o desenvolvimento do Programa, nessas duas áreas, deu-se por conta, segundo o Censo escolar INEP/MEC do mesmo ano, de uma baixa procura pelos cursos de licenciatura, principalmente nas áreas de Química, Física, Matemática e Biologia. A perspectiva inicial do Ministério de Educação com o Programa era atrair os jovens para que cursassem licenciatura e tivessem nela um adequado processo formativo. A partir de 2009, o Ministério fez progredir o Programa, publicando editais em todas as áreas do conhecimento.

No cenário de políticas públicas de fomento à educação, o PIBID constitui parte das ações do governo federal, que tiveram início em 2007, tendo em vista o desenvolvimento da Educação. Assim, o Programa integra - conjunto de reformas iniciadas naquele ano, com a promulgação de Diretrizes Nacionais para a Formação, em nível superior, de professores para a Educação Básica (Parecer CNE/CP n 009/2001 e Resolução CNE/CP n 1/2002). Nesta direção, o PIBID surge de um conjunto de objetivos que primavam por combater os problemas centrais relacionados à formação e à valorização dos professores da Educação Básica, em todo o território nacional.

Em julho de 2013, houve a publicação da Portaria no 96, com 0 propósito de atualizar e aperfeiçoar as normas do Programa, além de 
favorecer a valorização do magistério pela elevação da qualidade da formação inicial dos professores. Destaca-se o fato de que, segundo a referida portaria, essa formação deveria ocorrer, inicialmente, por uma boa articulação entre teoria e prática, entre a educação superior e a básica, isto é, entre a universidade e a escola básica. Como princípio norteador do Programa está o processo de formação, que passa a ser concebido pela inserção do licenciando na realidade escolar, em sua dinâmica organizativa, em um tempo e espaço que a universidade pouco alcançava. A valorização do magistério, nesta condição, passa pela perspectiva de se qualificar 0 docente para que o exercício do magistério atenda às reais necessidades da escola, com vistas à elevação dos índices de qualidade do ensino por ela ofertado.

A dicotomia existente na relação universidade e escola básica tem seus fundamentos, no PIBID, pela intersecção de teoria e prática, a partir da ideia de que a formação de professores e o desenvolvimento da docência precisam considerar os contextos "práticos", reais, da escola. Assim, na educação, o conhecimento teórico passa a ter valor, quando a possibilidade de sua aplicação se centra na condição prática que o sujeito tem de aplicá-lo e torná-lo significativo, sobretudo para o estudante. No Programa, a relação entre universidade e escola básica parece centrar-se numa perspectiva que considera o papel interseccional entre teoria e da prática educativa desenvolvida, também na universidade, mas vivenciada no contexto real da escola. O PIBID, mesmo sendo apenas um Programa, figura como uma possibilidade de articulação entre teoria e prática, aqui vistas como complementares e não como elementos segregados, uma vez que a vivência no espaço escolar passa a figurar como uma realidade de observação e de desenvolvimento de experiências que emergem das atividades práticas que o licenciando poderá empregar na escola.

Desse modo, a realidade escolar, entendida na metáfora do "chão da escola", torna-se um espaço por meio do qual os licenciandos, no PIBID, passam a vivenciar e compreender a docência no contexto prático onde ela ocorre. A consequência disso é que os participantes do Programa, 
colaboradores deste estudo, em específico, possibilitam reflexões na universidade, trazendo, em alguns contextos, o debate que permeia a relação teórico-prática, para o interior da academia, e fazendo aflorar, ainda que de modo pontual e contextual, em alguns poucos componentes curriculares, as discussões da formação de professores sob a perspectiva da vivência na/da profissão. O problema é que o PIBID não é uma política de formação direcionada a todos. Limita-se ao status de um Programa que, em tal condição, não atende a totalidade de estudantes da licenciatura, além de voltar-se, também, para outros objetivos, como o de oferecer bolsas para a permanência do estudante no curso de graduação. Isso tem gerado críticas ao PIBID, por entendê-lo no lugar de um simples Programa que passa, em alguns contextos, a ser considerado atrativo, não pela aprendizagem que promove, mas pela condição de ofertar uma bolsa aos seus participantes.

Segundo Silva (2017), mesmo sendo apenas um programa, o PIBID é concebido pela política governamental na condição de integrar ações de melhoria da educação nacional, constituindo-se, assim, em um importante passo para pensar a formação inicial para a docência no âmbito das universidades brasileiras. Talvez o Programa tenha sido pensado e desenhado pelo fato de haver um notório distanciamento entre a universidade e a escola, no que tange à compreensão acadêmica dos reais problemas e dilemas enfrentados pela educação básica. Os objetivos do Programa visam, entre outras coisas, potencializar a formação inicial de professores da Educação Básica, considerando que esta formação precisa acontecer também na escola e em seu cotidiano. Nesta direção, o Programa ganha força, na medida em que se propõe a realizar uma aproximação da universidade com a escola básica, não pela condição de que a universidade se proponha a ensinar a escola a realizar o seu trabalho, mas como uma forma de estabelecer uma parceria que dê a ambas condições para a produção de um diálogo profícuo sobre como desenvolver uma formação para o exercício da docência que agregue qualidade e compromisso social. 
Assim, o Programa busca cumprir dois dos seus principais objetivos, diriamos até que os mais importantes, que são "promover a integração entre Educação Superior e Educação Básica; e também contribuir para a articulação entre teoria e prática necessárias à formação dos docentes" (BRASIL, 2013, p. 2). Deste modo, o anúncio pelo Ministério da Educação desses objetivos, por meio de uma portaria, atesta a condição de que a política de formação de professores, na licenciatura, ainda não cumpre essa articulação entre a universidade e a escola básica. O surgimento do PIBID e sua legitimação na LDB não deixam de ser uma tentativa de promover tal articulação, ou ainda, de aperfeiçoá-la, reconhecendo a escola, e consequentemente o seu cotidiano, como um lugar relevante para possibilitar a formação de professores no país.

O PIBID possui elementos necessários, visto que envolve o licenciando em formação, o professor da escola básica e o professor universitário, com vistas a prover condições reais, que garantam o desenvolvimento de uma formação inicial, fundamentada na temporalidade e no cotidiano da escola, de modo articulado aos propósitos das diretrizes da educação nacional. Pela condição de inserir o licenciando na realidade escolar, compreendida em sua temporalidade de ações produzidas por todo o ano letivo, e não em períodos específicos, o Programa visa introduzir um novo espírito na formação docente, favorecendo ao licenciando a compreensão da escola, em suas condições reais e temporais de funcionamento.

\section{APRENDIZAGENS EXPERIENCIAIS DA DOCÊNCIA: relaçōes homológicas no fazer educativo}

A relação teoria e prática são basilares para o processo de formação docente, no qual o licenciando vivencia situações que perpassam pela compreensão de conceitos e estudos necessários inerentes ao ofício do professor. Nesse caso, quando o estudante passa pelo estudo teórico e começa a vivenciar a rotina escolar com todas as dinâmicas e realidade, este inicia um processo de relacionar o que foi aprendido na instituição universitária com as experiências profissionais adquiridas na escola. 
As práticas formativas têm como objetivo proporcionar vivências que configurem na vida e crescimento profissional do indivíduo. A complexidade existente no período de formação inicial consiste num diálogo coerente entre esses dois polos, teoria e prática, que permite ensinar com a intencionalidade, de incentivar a integração entre o estudo teórico e o exercício prático. De acordo com o que Gatti (2019) afirma, a experiência oriunda das vivências da prática são fundamentais para o professor em formação inicial. Sobre isso, nos diz essa autora:

Assim, o conhecimento-base na formação deve constituir-se a partir de experiências e análises de práticas concretas que permitam constante dialética entre a prática profissional e a formação teórica e, ainda, entre a experiência concreta nas salas de aula e a pesquisa, entre os professores e os formadores universitários (GATTI, 2019, p. 187).

Por meio das afirmações de Gatti, entende-se que a formação inicial é voltada a meios variados que conversam entre si, no qual o sujeito é responsável por vivenciar experiências da maneira mais significativa possível.

O período das atividades práticas funciona como elemento articulador, o qual tem o objetivo de realizar a imersão do licenciando no contexto da rotina prática do professor. Isso, de certa forma, é um modo de aprendizagem, pois o estudante além de vivenciar o meio, constituirá ações docentes de modo reflexivo apoiadas em conceitos teóricos específicos da área.

Desse modo, Gatti (2019) menciona que o indivíduo inserido no cotidiano escolar toma a prática como base para analisar os fatos apresentados e interpretá-los considerando a sua experiência teórica. Logo, o meio acadêmico se concentra em dispositivos; casos de ensino, diários reflexivos, portfólio, observação de sala de aula, dentre outros, que auxiliam o indivíduo a identificar essa relação teoria e prática.

Logo essas concepções sobre o movimento da imersão na prática emergiram como centralidade nas narrativas dos nossos colaboradores. Durante a entrevista, os sujeitos foram revelando pontos relacionados ao assunto discutido e por meio dos relatos as bolsistas evidenciaram as 
realidades instituídas neste universo. Inicialmente a bolsista Luana ${ }^{3}$, considera que:

\begin{abstract}
A gente passa a perceber que nem tudo que está na teoria a gente vai conseguir colocar em prática. Então a gente pensa assim, poxa eu critiquei o tempo todo, mas eu enquanto docente tomaria essa postura nessa situação. Então a gente percebe que por mais que a gente critique a postura do outro professor, mesmo estando em formação, a gente agiria daquela forma. O que a gente acaba tomando medidas provisórias, toda ação gera uma reação. Então a gente reage de impulso, mas foi gratificante justamente por isso, porque a gente começa a perceber através da observação do professor que a teoria, ela é muito linda mas a prática é uma outra história e eu entrei com essa visão né, de que tipo eu estou observando e relacionava muito, mas ao conviver com a professora a gente acaba socializando muito, eu percebi que essa teoria ela é muito linda, mas não é a base, sabe pra realidade da sala de aula, a realidade dos alunos (Entrevista narrativa, 2020, Luana).
\end{abstract}

No geral, basicamente pelo que foi relatado pela estudante é uma desilusão de que as expectativas estudadas na teoria não são alcançadas e para essa estudante chegar a essa conclusão precisou relacionar seus estudos teóricos com suas vivências na escola. Na compreensão sobre a relação teoria e prática, esses momentos de aprendizagens no cotidiano escolar proporcionaram a estudante, construções de concepções a respeito das práticas realizadas do professor, em que esta diz que ao perceber que não é possível colocar em prática tudo que está na teoria, até mesmo as críticas mencionadas sobre algumas ações tomadas pelos professores são levadas em consideração. Nesse sentido, a relação homológica se estabelece não por conceber a ideia de imitação do fazer do professor, mas por poder refletir sobre uma atitude pedagógica e sobre ela construir saberes próprios.

De certo modo, a dimensão da prática congrega elementos que fazem o estudante produzir uma teoria sobre o ensino e sobre como ele lida com as acontecências da escola. Assim, toda prática é uma teoria que se arregimenta nos princípios da vivência escolar, logo das aprendizagens

\footnotetext{
3 De acordo com recomendações do comitê de ética, que aprovou a referida pesquisa da qual se originou o presente artibo, foram utilizados nomes fictícios a fim de preservar a identidade das colaboradoras.
} 
experienciais tecidas no cotidiano da escola. Nessa mesma direção, Silva (2017, p.174) afirma que

(...) o licenciando é tocado por situações que the acontecem na sala de aula, na tessitura da docência que se constitui na trama do cotidiano escolar. Talvez seja por essa condição e imersão no chão da escola que o licenciando consiga perceber o outro, neste caso o aluno e o professor regente, em suas necessidades reais da docência.

Diante das possibilidades de aprendizagem da docência no campo escolar, os professores em formação inicial, participantes do PIBID, veem-se na condição de produzir desconstruções e ressignificações de suas concepções, inclusive em torno da relação teoria e prática. Isso faz com que o licenciando em formação construa sua própria identidade profissional de modo mais significativo. Nessa dinâmica, o licenciando também está aprendendo por homologia, pois de qualquer modo ela ainda está realizando esse processo com o outro que, mesmo que indiretamente, a professora em exercício proporcionou a Luana refletir sobre sua forma de pensar e criticar.

Sendo assim, a imersão do licenciando no ambiente escolar possibilita que essa relação teoria e prática seja percebida do jeito que ela ocorre, pois é nesse espaço e observando as práticas dos professores que os mesmos se reconhecem como tal e constroem seu ser profissional. É através da produção de conhecimento empírico sobre o fazer educativo que o licenciando se caracteriza como sujeito autônomo, gerador de aprendizagens experienciais para si, logo capaz de produzir novas ideias, críticas e argumentos. Isto concebido visibiliza-se na narrativa de Luana, que aborda as aprendizagens tecidas na organicidade do Programa.

Como a gente no PIBID tinhas reuniões quinzenais, a gente também recebia formação né?! Então a gente tinha formação com a nossa coordenadora geral nessas quintas-feiras e a na escola a gente ia dois dias, um dia a gente planejava, e no outro dia a gente executava o que era planejado. E eu acabei aprendendo assim, através dessas formações de quinta feira e através dessas observações mesmo. Eu acho que a observação, ela é o ponto crucial, a gente aprende, eu acho que a teoria e a prática elas não se separam né? A gente escuta isso o tempo todo, mas a prática, eu 
acho que é justamente na prática que a gente consegue visualizar as coisas de fato e eu acho que aprendi por meio da observação em si, de viver cada coisa ali (Entrevista Narrativa, 2020, Luana).

A partir desse relato, a prática da observação se configura como uma ferramenta fundamental para relacionar a teoria e a prática, condição que possibilita ao licenciando a presencialidade na realidade escolar, em que vivencia as práticas docentes, podendo identificar as dinâmicas, organizações e rotina do espaço educativo e, além disso, adquirir aprendizados que proporcionem uma melhor forma para exercer a futura profissão. O ato de observar é fundamental para analisar e compreender as interrelações dos indivíduos e do ambiente em que estes se socializam. Ele indica a condição fundante de desenvolvimento de aprendizagem experiencial, que se dá na e pelas relações homológicas.

Seguindo nessa perspectiva, a Bolsista Raissa traz como a prática de observar fez a mesma estabelecer relações com os estudos teóricos;

Eu acho que o momento que comecei a enxergar assim a teoria na prática desde o início, na observação na escola que ali já via muita coisa relacionada à prática, a psicologia da educação, muita coisa relacionada a relação família escola e durante 0 um ano PIBID possibilitou cada vez mais essa relação professor aluno. Também, psicogênese da língua escrita, eu conseguia ver e identificar o nível alfabético da criança estava e através da prática ali, na sala de aula tentando auxiliar nas dificuldades que as crianças na leitura e na escrita (Entrevista narrativa, 2020, Raissa).

A observação é o modo pelo qual Raissa expressa as aprendizagens que logra na relação com a professora, com o cotidiano escolar, sobretudo é o modo pelo qual ela aprende conceitos centrais dos processos de aquisição da linguagem, tendo em vista a aplicabilidade desse tema no processo de alfabetização. Assim, a estudante estabelecia relações no âmbito escolar, de forma a gerar aprendizagens que, consequentemente, tornavam-se cada vez mais significativas, pois ao realizar esse movimento esta tem uma visão ampla de como funciona de fato a realidade escolar. E isso é essencial para a formação e construção de um professor reflexivo, 
pois, permite que durante a formação construa-se uma compreensão da pluralidade existente na escola.

Logo, a prática de observação consequentemente nos leva a analisar, de modo mais acentuado, as complexidades existentes na escola e na própria prática docente, possibilitando que esse estudante reflita em torno dos principais temas que norteiam a educação, uma ação extremamente necessária na formação docente.

De acordo com a bolsista Raissa, "O PIBID me possibilitou enxergar a teoria através da prática, eu tinha um olhar de estudante e depois que eu saí do PIBID, eu tive o olhar de professora, olhar de docente" (Entrevista narrativa, 2020, Raissa). Tal narrativa revela o potencial formativo do PIBID, que possibilitou o engendramento de compreensões em torno da travessia formativa, a qual foi necessária para possibilitar a dimensão compreensiva do ser docente. Ao vivenciar o programa, desenvolver as atividades e perceber a teoria presente naquele espaço, a estudante experienciou situações que the possibilitaram ampliar sua visão, permitindo analisar o contexto com uma postura docente. Diante disso, percebe-se que 0 processo de relação teoria e prática configura a construção da identidade docente. Tal entendimento se identifica nas escritas de Silva (2017), que arrola percepções do modo como a identidade docente se define. Assim, nas palavras do referido autor,

(...) a construção da identidade docente é defendida, portanto, como produto de um processo complexo, que se sustenta em dimensões que vão desde a aceitação dos valores e princípios da profissão, vistos no cotidiano da escola, indo até o desenvolvimento de experiências do ser professor no PIBID, tendo em vista que essas são frutos das vivências dos licenciandos com os professores, na execução de sua atividade pedagógica, como também o são em certas ações que os licenciandos, supervisionados pelos professores que os acompanham, desenvolvem na escola, logo pela autoconsciência que é produto das reflexões que o licenciando elabora sobre a iniciação à docência, percebendo-a como um reflexo da sua forma de pensar e de agir (SILVA, 2017, p. 197).

Sendo assim, compreende-se que Silva (2017) defende uma vertente de que a identidade docente é justamente derivada de uma aprendizagem 
experiencial, tecida por ações dentre as quais são peculiarizadas vivências e relações tidas no ambiente escolar. Outro fator importante a se destacar são as reflexões e autoconsciência que o indivíduo adquire, o que se constata que essa formação constituída nas travessias do cotidiano escolar tem um caráter extremamente singular, pois cada um ao viver uma experiência terá umas considerações e aprendizagens diferentes em torno dela.

Paulo Freire (1996), afirma nem tudo que é estudado na teoria necessariamente estará aplicado na prática, pois tudo depende do contexto em que a escola está inserida. É o caso, por exemplo, de escolas de comunidades carentes, em que as estruturas físicas, pedagógicas não são, necessariamente, previstas numa teoria da aprendizagem ou dos processos de ensino de que fazem os professores. No entanto, o contexto requer que os professores realizem outros investimentos pedagógicos, que necessariamente não emergiram das teorias estudadas para essa finalidade. É o que se observa nas acontecências da profissão docente, em que, professores, no exercício de sua função, precisam encontrar subterfúgios para ensinar em contextos de adversidade.

O ensino em situações de vulnerabilidade social, como escolas de comunidades em que a violência é uma constante, em que crianças e educadores necessitam criar modos próprios para desenvolver o processo de ensino-aprendizagem. A universidade não ensina ao professor em formação inicial como ele vai lidar com situações imprecisas, incertas, de por exemplo, de ensinar a criança por meio de estratégias didáticas a produzir outros significados, além do que elas conhecem pela situação cotidiana em que vivem imersas, para termos como violência, agressão moral, abuso sexual, abuso de poder, etc. Esse tipo de ensino só se efetiva na relação que o professor exerce com a criança, com a comunidade e com o contexto em que ela vive, criando um modo próprio de exercer uma prática, que nem sempre ganha luz de teorias estudadas. A prática, nesse sentido, passa a ser a grande teoria que inspirará outras tantas práticas, mas que emergem das acontecências da própria escola, da própria comunidade, logo do contexto em que cada criança vive. 
Desse modo, a teoria obtém um papel formador, mediador e realiza uma compreensão crítica e necessária para atender as necessidades específicas do ambiente da sala de aula e das práxis implementadas pelos docentes. Ao compartilhar da práxis, o licenciando partilha de ações que podem ser transformadoras, autorreflexivas e críticas, provocando uma consciência e aprendizados que corroborem para a autonomia do licenciando. Diante disso, Raissa diz;

Então, posso dizer que tive uma aprendizagem significativa relativamente positiva e relativamente negativa porque através do PIBID eu vi coisas teóricas que eu estudei que eu estudo na teoria na universidade e coisas assim do senso comum que muitas das vezes o professores fazem e não tem consciência da gravidade que ele pode causar na criança tanto psicológico quanto em termo de aprendizagem (Raissa, Entrevista Narrativa, 2020).

Logo, por meio dessas discussões compreendemos que a relação teoria e prática é marcada por uma grande significância para o período de formação docente, assim como na aprendizagem por homologia, pois o licenciando além de manter acesa a aprendizagem pela relação com o outro, este está formando uma autonomia e criticidade indispensáveis.

Ao considerar a gravidade de ações que os professores em exercício desenvolvem, Raissa dá indícios de que a reflexão do ser docente transversaliza a construção de princípios que ela constrói para si. Nesse aspecto, a compreensão das teorias implica um valor fundante que serve de base para as ações que os professores desenvolvem. Não agir em senso comum, significa agir com consência, como propõe Paulo Freire (1996), implica em ter conhecimento das ações e dimensões que a teoria possibilita para desenvolvimento de uma prática coerente e alicerçada nos princípios da responsabilidade e do conhecimento científico no campo educacional.

Aprender com o outro, significa também, observar as atitudes do outro e ter condições de produzir uma análise que evidencie os êxitos, como também os equívocos, de práticas que os professores executam. Em meio a esse estudo da aprendizagem por homologia, compreende-se que para ocorrê-la será necessária uma relação direta do professor com o 
licenciando. Sendo assim, a maneira como é construída e mantida essa relação influencia no processo da constituição docente. Com isso, Silva (2017, p.169) afirma;

A vivência e a experiência produzidas no ambiente escolar são elementos basilares para que o sujeito se reconheça em um processo relacional em que a identidade vai ganhando sentido para si mesmo, sobretudo pela relação com o outro.

Nesse contexto, compreende-se que o processo de interação com a rotina escolar, as práticas pedagógicas e a convivência com os outros sujeitos pertencentes ao lugar faz com que surja o auto-reconhecimento da sua identidade docente. A relação professor-aluno segue uma base dialética e de influência mútua, pois através das práticas do professor, podese fazer com que o licenciando construa possibilidades de aprendizados significativos. Tal situação faculta a produção, por parte do professor em formação inicial, a construção dos processos de autonomia e de presença ativa na formação universitária.

Em vista disso, no PIBID o licenciando mantém uma relação contínua com o seu professor estando propenso a aprender por homologia, pois à medida que a qualidade da relação professor-aluno se torna positiva, consequentemente ela será dialógica e afetiva $\bigcirc$ que influencia significativamente no desenvolvimento integral dos sujeitos. A possibilidade de ver de como o professor organiza sua rotina, planejamento para aulas, a interação com as crianças, desenvolvimento de abordagens de ensino, entre outros fazem com que o licenciando aprenda como é ser professor, fato que evidencia o modo próprio de desenvolvimento de aprendizagem experiencial da docência, por processos homológicos.

Nesse interim, a bolsista Luana, concebe que:

Acho que um dos pontos mais importantes da professora na sala de aula era a empatia. Se colocar no lugar do outro, ou seja, ela percebia o aluno, ela entendia que precisava atender aquele aluno e que por mais que exista um currículo e uma hierarquia acima da gente, eu preciso fazer o que é, o que me é conveniente no momento, porque as vezes tem que seguir um plano de aula, mas surge uma brincadeira entre os alunos e eu preciso falar de bullying, 
eu paro o conteúdo da aula. Ela tinha essa sensibilidade de perceber que nem sempre ela precisava seguir um cronograma da aula, se houvesse necessidade de discutir uma outra questão, ela discutiria e isso eu aprendi na relação com ela, vivendo cada situação ali, entende? (Luana, Entrevista narrativa, 2020).

Diante deste relato, percebe-se que ao vivenciar e criar um vínculo e diálogo com sua professora, Luana se atentou em aspectos extremamente pontuais que foi a empatia e olhar atento ao aluno. Bem como afirma Freire (1996, p. 113), "o educador que escuta aprende a difícil lição de transformar o seu discurso, às vezes necessário, ao aluno, em uma fala com ele". A narrativa possibilita inferir que as práticas docentes claramente fazem diferença para sua construção de saberes docentes, pois a formação profissional é constituída de saberes que se constroem nas acontecências da profissão, logo numa tessitura que considera o inesperado, a inventividade e os processos autênticos que se geram no próprio movimento da docência.

Assim como a bolsista menciona, a professora supervisora também destaca em seu relato a necessidade de manter boas relações afetivas com seus alunos e isso contribuiu para que as licenciandas compreendessem essa importância de manter uma postura reflexiva. "Na escola a gente segue adotando uma postura dialógica baseada na proximidade e empatia, buscando compreender as complexidades e os saberes um dos outros" (Eliene, Entrevista narrativa, 2020). A percepção da professora Eliene aponta para uma compreensão dialógica defendida por Freire (1996), momento em que o autor considera que:

A construção de relações dialógicas sob os fundamentos da ética universal dos seres humanos, enquanto prática específica humana implica a conscientização dos seres humanos, para que possam de fato inserir-se no processo histórico como sujeitos fazedores de sua própria história (FREIRE, 1996, p. 10).

Logo, a postura dialógica gera ramificações na relação professor aluno que possibilitam a constante aprendizagem entre os sujeitos. De acordo com Silva (2017), a relação professor e estudante se concentra em o aluno estar comprometido em aprender e ao professor ensinar e aprender. 
No entanto, nessa imersão no meio escolar o licenciando busca compreender múltiplas outras dinâmicas que se visibilizam nas relações estabelecidas e nos papéis sociais do professor e do aluno. Nessa realidade, o licenciando ocupa uma posição de observação, na qual sua atenção está concentrada aos detalhes da relação pedagógica desenvolvida na sala de aula.

Segundo Silva $(2017,169)$,

O PIBID permite que haja relações interpessoais entre o professor que está em pleno exercício e o licenciando que vai, a partir da socialização, fazendo escolhas e desenvolvendo um saber sobre a profissão docente.

Nesta situação, percebe-se a relevância que as relações interpessoais exercem no modo de como será a experiência no campo docente. Em vista disso, as configurações das identidades são resultados das escolhas e influências das relações interpessoais que estabelecemos ao nosso redor. Luana faz uma menção relevante que reflete essa compreensão sobre as relações interpessoais, pois concebe que através da convivência com a docente houve a possibilidade de conhecer, de fato, como era a abordagem e interação que a professora tinha com a turma. Em sua narrativa ela faz a seguinte reflexão:

Assim, eu mudaria algumas atitudes dela em relação a metodologia, de controle entre aspas, mas tipo assim; manter a sala organizada, porque os meninos acabam bagunçando muito e aí pra ela manter isso ela utilizava ameaça, ou seja, falava: vou levar na diretoria. Isso seria uma coisa que eu não faria, né, tipo assim, eu acho que, as crianças precisam ter autonomia assim como a professora precisa ter né? E pra isso eu acho que deve existir uma relação de respeito, se eu respeito os alunos, consequentemente eles vão me respeitar e eu acho que é isso a base de um bom convívio, diferente dela que, ameaçava, nesse sentido (Luana, Entrevista narrativa, 2020).

Neste relato, percebe-se que a construção argumentativa que a estudante usa para comentar sobre as atitudes da professora reflete 0 quanto foi importante esta ter experienciado $O$ movimento das acontecências da sala de aula. É nesse movimento experiencial do 
cotidiano da profissão, que a relação por homologia cria condições para que a licencianda desenvolva saberes e aprendizagens próprias, que revelam o seu olhar singular sobre como lidar com certas situações. Mesmo que as ações observadas na prática da professora sejam indicativas de um modelo de atitude incoerente, a estudante percebeu que o modo como mantemos a relação com o outro reflete na forma de construir para si aprendizagens.

O PIBID além de proporcionar essa relação professor aluno também contribui para o que o licenciando entre em contado com as crianças que, de certo modo, criam condição para que o professor em formação inicial possa aprender como ensiná-las, qual método mais adequado e ter olhar atento para cada subjetividade delas. Sendo assim, Isabela em sua narrativa evidencia alguns aspectos interessantes.

\begin{abstract}
As dicas eram fugir do óbvio, parar de fazer atividade de cobrir e de transcrever a palavra porque eles estavam em processo de alfabetização e minha sala era do primeiro ano e fazer atividades diferentes para cada aluno, porque cada um deles estava em uma fase na escrita. Alguns deles tinham dificuldade ali na sala de aula e eu tinha uma aluna que era a primeira vez que ela estava em uma escola. Então ela não tinha tido contato antes nenhum com as letras e números e ela confundia muito isso, então uma das dicas da professora era fazer um material e mostrar por exemplo, fazer a letra A, aí eu fazia de EVA, o que eu tivesse para aquela aluna pegar ali na mão, ficar e também eu colocava muito imagens. A professora falava para colocar muito imagens e fazer com eles para relacionar. Por exemplo, eu colocava uma imagem da abelha, então ela tinha que associar com a letra A, B, no caso ela não sabia ler, mas ela sabia que aquilo era uma abelha, aí eu pegava as letras para ela fazer correspondência com as vogais[...] (Isabela, Entrevista narrativa, 2020).
\end{abstract}

Após esse relato, percebe-se que essa proximidade que a estudante teve foi muito relevante para sua formação docente. No seu relato é evidente que ela teve o cuidado e o olhar atento para especificidades da criança, adequando o planejamento de atividade para atender as dificuldades da aluna. Outro fato foi que a professora também ofereceu todo o suporte para que a bolsista Isabela conseguisse desenvolver as atividades. Portanto, através dessas discussões e dos relatos apresentados, 
visualiza-se que o campo da aprendizagem homológica tem as relações interpessoais como um elemento indispensável para o seu desenvolvimento.

Ademais, os saberes da docência vão se consolidando enquanto aprendizagens experienciais tecidas na relação com o outro. Assim, a homologia se dá como processo vital em que professores em exercícios na escola básica e licenciandos criam condições de produção de saberes a partir de atitudes colaborativas e dialógicas.

\section{CONSIDERAÇÕES FINAIS}

O estudo possibilitou concluir que as relações que professores em exercício e licenciandos estabelecem na vivência do cotidiano escolar proporcionam uma formação crítica, reflexiva, autônoma e dialógica, o que consequentemente possibilita um desenvolvimento profissional e pessoal. Trata-se, portanto, de modos operativos em que licenciandos aprendem a ser professor pela relação com o outro, vivenciando práticas no cotidiano da profissão, a partir das acontecências. Tal situação faculta as aprendizagens experienciais da docência, tecidas nas ações relacionais da escola, mas também pelo adensamento dos estudos produzidos na universidade.

Nesse contexto, a aprendizagem da docência é fruto de relações que são constituídas nos percursos de formação universitária, nos quais se inscrevem, também, o PIBID. A medida que essas relações vão sendo vivenciadas, o estudante constrói uma compreensão crítica sobre os conceitos docentes. Tal situação ocasiona uma consciência do que fazer e como fazer a prática docente. Nesse caso, o PIBID é o agente proporcionador, que oferece uma condição aos licenciandos de experienciar o ambiente escolar e entender como a docência é aplicada na prática.

No movimento da prática pedagógica, o professor desenvolve um saber através das relações interpessoais entre os demais sujeitos, junto com as dinâmicas que ocorrem na escola. O PIBID faculta ao licenciando condições de relacionar seus estudos feitos na universidade com as experiências tidas no contexto em que está imerso. A homologia torna-se 
fundante para se pensar o processo de formação de professores, principalmente pelas condições de aprendizagem que se criam nas ações relacionais.

As narrativas possibilitaram compreender que ao se relacionar com os professores e no cotidiano escolar, as licenciandas conseguiam fazer diariamente a relação em todas as práticas dos professores, com apreensões metodológicas sobre princípios operativos de como lidar com os estudantes da escola básica face às suas necessidades emergentes de aprendizagem. Assim, as narrativas evidenciaram aprendizagens logradas em torno de metodologia, posturas e atitudes que dialogavam com as discussões feitas no campo universitário. Isso proporcionou que as bolsistas vissem uma coerência e sentido do que havia sido estudado na teoria.

Nesse processo relacional, o estudo permitiu perceber como o PIBID permite que haja relações interpessoais entre o professor que está atuante em sua profissão e o licenciando bolsista, por meio de processos de socialização e de diálogos, a partir dos quais o estudante faz escolhas e desenvolve um saber sobre a profissão docente. Com isso, os estudantes constroem sua identidade professoral, emitindo opiniões e posicionamentos sobre como o professor supervisor aplica suas práticas em sala de aula. Tal condição sugere que no PIBID se gere um processo de formação, pelo qual os professores em formação desenvolvam princípios de autonomia que se ancoram nas escolhas que cada sujeito faz ao aprender e a conviver com determinadas situações.

Portanto, entende-se que essas relações fazem parte do cotidiano docente. Assim, no âmbito do PIBID, essas estudantes e a professora as visualizaram e perceberam que é preciso manter uma relação dialógica, afetiva e respeitosa entre os pares, pois além de fazer com que a aprendizagem ocorra da melhor maneira possível, isso gera condições de motivação para a docência. A docente colaboradora ao apresentar diariamente suas práticas mostra também como essas estudantes devem manter os seus relacionamentos com os alunos quando estiverem exercendo a profissão. A pesquisa também apontou que o PIBID auxilia as estudantes a 
desenvolverem uma aprendizagem experiencial, fincada nos propósitos do aprender com o outro e de construir práticas de como estabelecer relações com as crianças.

\section{REFERÊNCIAS}

BRASIL. Ministério da Educação - Proposta de Diretrizes para a Formação de Professores da Educação Básica em Nível Superior. Parecer CNE/CP $n^{\circ}$ 009/2001 e Resolução CNE/CP n 1/2002 Brasília, maio de 2002.

BRASIL, Ministério da Educação. Portaria n 096, de 18 de Julho de 2013. Regulamento do Programa Institucional de Bolsas de Iniciação à Docência PIBID. Brasília, 2013. Disponível em: <https://www.in.gov.br/materia//asset_publisher/KujnOTZC2Mb/content/id/30798135/dol-2013-07-23portaria-n-96-de-18-de-julho-de-2013-30798127>. Acesso em: 14 jul 2020.

DUTRA, E. F. Possibilidades para articulação entre teoria e prática em cursos de Licenciaturas. 2010. 354 f. Dissertação (mestrado em Educação) Programa de Pós-Graduação em Educação, Universidade Federal de Santa Maria, Santa Maria, RS, 2010.

FREIRE, P. Pedagogia da autonomia: saberes necessários à prática educativa. São Paulo: Paz e Terra, 1996. - (Coleção leitura).

GATTI, B. A. E.; BARRETTO S. S.; ANDRÉ, M. E. D. A.; ALMEIDA, P. C. A. Professores do Brasil: Novos Cenários de Formação, Brasília: UNESCO, 2019.

JOVCHELOVITCH, S.; BAUER, M. W. Entrevista narrativa. In: BAUER, M. W. et al. Pesquisa qualitativa com texto, imagem e som: um manual prático. Petrópolis, RJ. VOZES. 2002. $2^{a}$ ed.

RICOEUR, P. Teoria da interpretação. Trad. de Artur Morão. Lisboa: Edições 70, 1996.

SILVA, F. O. Formação docente no PIBID: Temporalidades, Trajetórias e Constituição Identitária. Tese (Doutorado em Educação). 220fls. Programa de Pós-Graduação em Educação e Contemporaneidade - PPGEduC Departamento de Educação. Universidade do Estado da Bahia, 2017.

SILVA, F. O.; RIOS, J. A. V. P. Aprendizagem experiencial da iniciação à docência no PIBID. Práxis Educativa (UEPG. Online), v. 13, p. 202-218, 2018. Ponta Grossa-PR. Disponível em: <https//doi.org/105212/praxeduc.v.13i1.0012>. Acesso em: 14 jul 2020. 
Recebido em: 23 de setembro de 2020

Aprovado em: 22 de outubro de 2020

Publicado em: 04 de novembro de 2020

(c) (1) (\$) 